Poznań Studies in Contemporary Linguistics 44(3), 2008, pp. 345-361

(C) School of English, Adam Mickiewicz University, Poznań, Poland

doi:10.2478/v10010-008-0017-8

\title{
PARTIAL CONTROL IS TRICKIER THAN WE THOUGHT
}

\author{
ANNA SNARSKA \\ Adam Mickiewicz University, Poznań \\ snarska@ifa.amu.edu.pl
}

\begin{abstract}
This paper discusses partial control, a notoriously intricate phenomenon. Brought to the linguistic limelight only recently (cf. Landau 2000), its bizarre nature renders it a real challenge to any theory of control. I contribute to the Agree vs. Move debate on control by making an empirical claim concerning cases of what I call Parasitic Partial Control Effects which are extremely problematic to Landau's Agree Theory of Control. To account for these facts, I propose a solution framed within the theory of control based on Move. Refining insights in Rodrigues (2007), I suggest that the licensing of the PC effect depends on the presence of the projection of wollP dominated by TP in the structure of the infinitive and the sideward movement of the DP controller from within the adjunct to the matrix. Thus, Landau's claim that partial control is licensed only in complements must be loosened (if not dropped).
\end{abstract}

KEYWORDS: PRO; control; sideward movement; pro.

\section{Introduction}

Control has always been intriguing. Unraveling the mystery behind the nature of the relation between a missing, non-lexical subject and its antecedent, i.e., the relation between PRO and its controller, proved a conundrum to every theory of control. ${ }^{12}$ A classic example of a control relation with PRO being co-indexed with another DP is illustrated in (1) below:

\footnotetext{
${ }^{1}$ At this juncture, I have to obligatorily mention the seminal works by Rosenbaum (1967), Chierchia (1984), Williams (1980), Chomsky (1982), Chomsky and Lasnik (1993), Martin (1996), Hornstein (1999) and Landau (2000), among others.

${ }^{2}$ This problematic state of affairs arose due to the fact that control proved eclectic: characterizable not only by pure syntax but also tainted by semantics and pragmatics.
} 
It is widely recognized that control comes in two flavors: obligatory control (henceforth, OC) and non-obligatory control (henceforth, NOC) (Williams 1980). While this distinction has been a recurring topic in a long history of generative grammar, recently a fresh idea has been thrust into the limelight posing a real challenge to any theory of control (Landau 2000), witness (2):

$$
\mathrm{John}_{1} \text { told Mary that he }{ }_{1} \text { wants }\left[\mathrm{PRO}_{1+} \text { to meet in the morning]. }{ }^{4}\right.
$$

Why is the sentence in (2) so problematic control-wise when juxtaposed with the runof-the-mill control as exemplified in (1)? In (1), we can see that the relation between PRO and its antecedent is that of identity with the disparate elements displaying the same indices. Turning now to the control relation in (2), the indices on PRO and its controller surprisingly do not match. It seems that the reference of the PRO only subsumes the reference of the controller but crucially does not exhaust it.

Although some sporadic examples of the phenomenon in (2) had been noticed earlier (Lawler 1972; Williams 1980; Martin 1996), it was Landau (2000) who first discussed the peculiar control relation at length, his work marking a quantum leap in the study of this atypical species of control. Using Landau's nomenclature, the control relation in (2) has come to be known as Partial Control (henceforth, PC) with (1) being dubbed Exhaustive Control (henceforth, EC). Let us take a more careful look at PC in (2). Here the matrix subject is subsumed under one larger group of individuals constituting the referent of the covert subject of the embedded clause. With the complement containing a collective predicate such as meet, this effect can be detected immediately. ${ }^{5}$ The exigencies of semantics of collective predicates (in brief, their subject must be semantically plural but need not display syntactic plurality) make us conclude that PRO has to necessarily be $\mathrm{PRO}_{1+}$ and that the matrix DP is incapable of functioning as the only controller of the embedded clause. A natural question that arises at this point is as follows: what is the mechanism for linking $\mathrm{PRO}_{1+}$ and its controller? Put differently, is

\footnotetext{
${ }^{3}$ I use the conventional null pronoun PRO in lieu of the subject for purely expository reasons, but it may as well be the case that PRO is phantasm, control being reduced to raising (e.g. Hornstein 1999; Manzini and Roussou 2000; Pires 2001; Polinsky and Potsdam 2002; Hornstein 2003; Bowers 2005) or requiring only a de-composition of $\theta$-roles (Janke 2008). On the whole, it is rather surprising that PRO at all functions in a minimalist setting taking into consideration the fact that GB-era (which posited PRO) is something of anachronism these (Minimalism-oriented) syntactic days. What is more, one of the most important works on control (Landau 2000 and subsequent) clearly set in a minimalist framework sticks firmly to the GB-formative.

${ }^{4}$ The linguistic context in (2) provides the necessary participants of the meeting other than the matrix controller. However, one should bear in mind that when such a context is missing, pragmatics will allow us to set up another one easily.

${ }^{5}$ Other collective predicates include gather, congregate, assemble, convene, the adverb together, etc.
} 
PC a syntactic phenomenon or does it perhaps fall within the ambit of both syntax and semantics? ${ }^{6}$

The chief aim of this paper is to argue against a purely syntactic analysis of PC which crucially pivots on an operation Agree holding between the matrix probe (functional head) and the embedded goal (T-Agr). It will be shown that it is not enough. Syntax of control itself (especially as perceived by the Agree Theory of Control (henceforth, ATC)) fails to explicate all the ins and outs of PC. Out of many, both conceptual and empirical, problems the Agree-centered control scenario has to struggle with, I will focus on one facet which, undoubtedly, calls into question the veracity of the ATC. I will introduce a new observation about PC into adjuncts clauses, or rather its specific subspecies that I call Parasitic PC Effects (henceforth, PPCE). The PPCE arise once adjunct control is coupled with PC in a complement clause. In such cases a parasitic PC reading is available within the adjunct clause, which is most surprising in light of the unavailability of run-of-the-mill PC into adjunct clauses. This state of affairs has farreaching consequences for the selection of the appropriate theory of PC. Obviously, the ATC has a problem predicting that such a parasitic version of this effect should hold. The goal (embedded T-Agr) in the adjunct clause, which acts as an island, cannot be accessed by the matrix probe $\mathrm{T}$. Thus, Landau treats adjunct control as a subspecies of NOC. To account for these seemingly problematic facts, I will propose a solution framed within the theory of control based on Move. Refining insights in Rodrigues (2007), I will suggest that the licensing of the PC effect depends on the presence of the projection of non-selected wollP (in the sense of Wurmbrand 2007) dominated by TP in the structure of the infinitive and the sideward movement of the DP controller from within the adjunct to the matrix. Crucially, the PC effect arises since the matrix controller originates in the adjunct clause as part of a complex DP which also contains a null associative plural pronoun adjoined to the DP controller. The DP, leaving the adjunct clause (sideward movement) on its way to the complement clause, strands the collective pro in the scope of woll, thus giving rise to PC. Furthermore, the associative pro in the adjunct clause can be licensed by the unselected woll $\mathrm{P}$ only when this licensing is subject to confirmation on the same DP by a selected wollP in the complement clause. The DP controller in the complement clause forms another complex DP in [Spec, vP] and once again it leaves the null plural pronoun behind while it moves to [Spec, TP], triggering another instance of PC.

This paper is structured as follows. First, I briefly outline the account of Partial Control as framed within the Agree Theory of Control (Landau 2000 and subsequent). Second, I attend to the Movement Theory of Control (henceforth, MTC) and its vision of the phenomenon in question (Hornstein 1999 and subsequent). Finally, I present (in-

\footnotetext{
${ }^{6}$ One cannot also definitely exclude the possibility that PC resists any systematic account largely reflecting
} its pragmatic origin (Bowers 2005). For a critique of this approach see Snarska (2007). 
convenient to the ATC) Parasitic PC Effects, proving that an analysis based on Move is able to account for the relevant data.

\section{Agree as a solution to $\mathrm{PC}$}

Let me now touch upon the rudiments of Landau's system built upon the operation Agree. As mentioned earlier, Landau (2000) bifurcates his solution to obligatory control which in his account consists of exhaustive control (EC) and partial control (PC). The EC verbs comprise implicative, aspectual and modal verbs, while the PC verbs are instantiated by factive, propositional, desiderative and interrogative verbs. A sample of each type of control is provided below, with (3a) and (3b) (repeated here for convenience) representing exhaustive and partial control, respectively:

(3a) $\mathrm{John}_{1}$ tried [PRO $\mathrm{PR}_{1}$ to kiss Susan].

(3b) $\mathrm{John}_{1}$ told Mary that he $\mathrm{1}_{1}$ wants $\left[\mathrm{PRO}_{1+}\right.$ to meet in the morning].

A fundamental assumption of Landau's analysis is that the distinction between the PC and EC effect boils down to a difference between tensed and non-tensed infinitives. ${ }^{7}$ Landau claims that only tensed infinitives evince partial control; that is, the tense specification of PC complements is (relatively) independent of the matrix clause. The rationale behind this fact is that in PC the embedded T moves to $\mathrm{C}$ precluding thus Agree from holding between $\mathrm{PRO}$ and a higher functional category $\mathrm{F}$ ( $\mathrm{T}$ in the case of subject control and $\mathrm{v}$ for object control) that also agrees with the matrix controller. ${ }^{8}$ (4a) represents the EC and (4b) the PC structure:

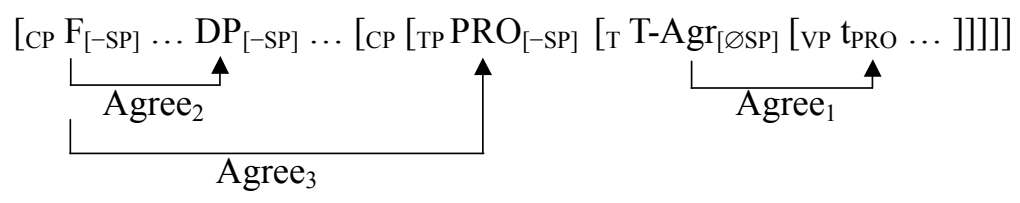

\footnotetext{
${ }^{7}$ That tense is crucial as regards control is not a new observation. It was Stowell (1982) who postulated that only control infinitivals are specified for tense, while ECM and raising infinitivals are devoid of it. This proposal was later utilized by Bošković (1997) and Martin (2001), among others.

${ }^{8}$ Bondaruk $(2004,2006)$ proposes a variation of Landau's account of PC readings for Polish, which finds showing no independent reflex of T-to-C movement. In the place of head movement, embedded T is bound by the matrix T or v. The problem is that this binding relation is subject to Minimality Effects and is suspiciously similar to Agree.
} 
(4b)

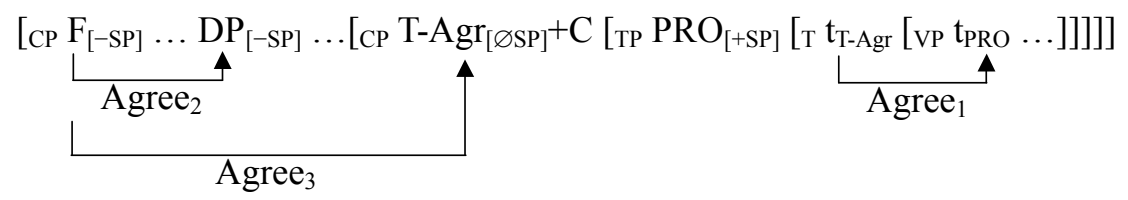

Three Agree operations apply in (4a) to match the features of F, DP and PRO. Agree $_{1}$ holds between PRO and embedded T matching the $\varphi$-features of the two elements and simultaneously checking PRO's null Case (Case being a reflex of $\varphi$-features on T). Agree $_{2}$ is established between matrix F (T/v) and a lexical DP and Agree $_{3}$ obtains between $\mathrm{F}$ and PRO. This licenses the $\mathrm{EC}$ reading and control understood as an indirect $\varphi$ feature sharing between the controller and $\mathrm{PRO}$ mediated through $\mathrm{F}$ participating in two Agree relations. In (4b), Agree $_{1}$, holding between $\mathrm{PRO}$ and T-Agr, establishes embedded agreement (followed by raising of PRO to [Spec, TP]) and Agree $_{2}$, obtaining between F and DP, gives rise to matrix agreement. Since PC complements are tensed, T-Agr must move to $\mathrm{C}$ to check C's uninterpretable T-feature, thereby reaching an edge position in which it is visible to matrix operations. Hence, Agree $_{3}$ holds between F and T-Agr adjoined to $\mathrm{C}$. The key element of this analysis is that PRO in PC is imbued with semantic plurality but, crucially, it partakes of syntactic singularity at the same time. So how is it possible that it co-exists with a semantically singular controller? The unpronounced subject, equipped with an inbred semantic plurality feature [+SP], agrees not with $\mathrm{F}$ but with embedded $\mathrm{T}$ which is $[\varnothing \mathrm{SP}]$ since it does not inherit $[-\mathrm{SP}]$ from $\mathrm{F}([-\mathrm{SP}]$ and $[\varnothing \mathrm{SP}]$ being non-distinct on functional heads). Thus, [ØSP] on T and [+SP] on PRO do not conflict (given that they are not opposite), begetting PC effect. ${ }^{9}$

Landau (2004) introduces a number of modifications to his calculus of control, though the three key assumptions are still strictly observed. Regarding PRO itself, the conjecture is that it is a phonetically null SE-anaphor (Reinhart and Reuland 1993). On the whole, obligatory control is still deemed to be an instance of Agree but, importantly, the licensing of PRO is tuned to the interplay between Agr ( $\varphi$-features) and T(ense) features both on $\mathrm{I}^{0}$ and $\mathrm{C}^{0}$ in the embedded clause and the movement of $\mathrm{T}$ to $\mathrm{C}$ is abandoned in favor of feature sharing between these two heads.

\footnotetext{
${ }^{9}$ This analysis of PC leads to the following incorrect expectation: every PRO embedded under a PC verb should license both an EC and a PC reading to the same degree, assuming that both [-SP] and [+SP] on PRO are compatible with $[\varnothing \mathrm{SP}]$ on $\mathrm{T}$ moved to $\mathrm{C}$. This does not seem to be the case and the $[+\mathrm{SP}]$ reading is hard to obtain on (ii) below:

(i) John 1 wants $\left[\mathrm{PRO}_{1}\right.$ to write a letter $]$

(ii) $\mathrm{John}_{1}$ wants $\left[\mathrm{PRO}_{1+}\right.$ to write a letter $]$

A correct account of this fact requires a correlation between the semantics of the embedded predicate, selecting for a $[+\mathrm{SP}]$ subject, and $\mathrm{T}$ to $\mathrm{C}$ movement. This issue is also addressed in later versions of the ATC theory.
} 
Furthermore, at the heart of the new control module lies the fact that the licensing of PRO is a product of the interaction between the features on $\mathrm{I}^{0}$ and $\mathrm{C}^{0}$ and DP-features $([+R]$ on independently referential DPs and $[-\mathrm{R}]$ on anaphoric DPs) with the resultant conjecture:

$$
\begin{aligned}
& \text { R-assignment Rule } \\
& \text { For } \mathrm{X}_{[\alpha \mathrm{T}, \beta \mathrm{Agr}]}^{0} \&\left\{\mathrm{I}^{0}, \mathrm{C}^{0} \ldots\right\} \text { : } \\
& \quad \varnothing \rightarrow[+\mathrm{R}] / \mathrm{X}^{0}{ }_{L}, \text { if } \alpha=\beta=\text { “+” } \\
& \quad \varnothing \rightarrow[-\mathrm{R}] / \text { elsewhere }
\end{aligned}
$$

These assumptions give rise to the following Agree relations in the case of PC:

$$
\mathrm{PC}
$$

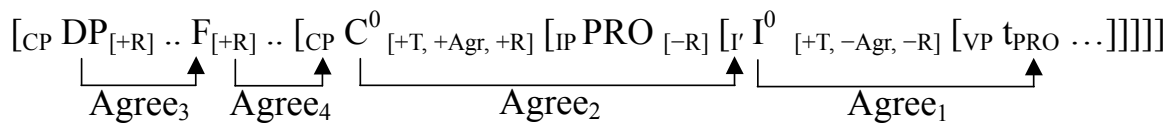

Details aside, four Agree relations hold in (6). The PC effect itself receives a new guise. It arises since PRO carries, in the place of the semantic plurality feature [+/-SP], the [+Mer] (eology) feature (following Sauerland and Elbourne 2002) and the controller is $[-\mathrm{Mer}]$.

Finally, Landau (2007), building on Landau (2000, 2004), advances the claim that obligatory control utilizes two routes: either direct Agree with PRO (PRO-control in EC cases) or Agree mediated by the infinitival Agr-bundle on C (C-control in PC). Landau uses the facts of case transmission in Russian to substantiate the claim that PC entails $\mathrm{C}$-control. But what is the precise reason behind the availability of C-control in PC? It is argued that everything boils down to the presence of [Mer] on C.

(7) Subject PC in Russian: (Landau 2007:41)

(7a) Predsedatel' predpočel sobrat'sja vsjem/*vsje v šest'.

Chair.NOM preferred to-gather all. DAT/*NOM at six

'The chair preferred to all gather at six.'

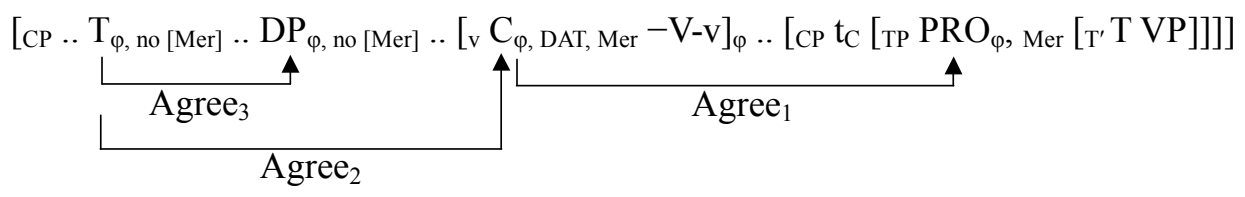


Given that the embedded $\mathrm{C}$ is tensed, it is selected by the matrix verb with a $\varphi$-set. It also carries [Mer] pointing to its semantic plurality. What is also significant is that the Complementizer, being null, must undergo cliticization to the higher verb. Its host, light $\mathrm{v}$, is specified for $\varphi$-features which differ from the $\varphi$-set of the dominated C (it contains [Mer] which is absent from v). Three Agree operations apply to license PC. Agree ${ }_{1}$ holds between $\mathrm{C}$ and PRO, valuing $\varphi$-features and [Mer] on PRO. Agree ${ }_{2}$ is established between the matrix T and DP which are semantically singular (no [Mer]). Agree ${ }_{3}$ holds between the matrix $\mathrm{T}$ and $\mathrm{C}$, the latter being semantically plural ([Mer]). The resulting Agree will focus on $\varphi$-features, ignoring [Mer]. Consequently, the PC effect arises as a result of the intervention of C ([Mer]) within the chain of Agree relations between the [Mer]-less controller and a [+Mer]-specified PRO. ${ }^{10}$

All in all, much as Landau's meticulously constructed syntactocentric theories vary in some respects, they all stress one thing: PC is an instance of Agree and, with the latter being a subpart of the minimalist version of Move (Chomsky 2000), it must be sensitive to islands.

\section{Move-centered vision of PC}

\subsection{The Meaning Postulate}

At first glance, the existence of partial control appears devastating to the MTC which definitely discards the existence of the control module while claiming that PRO is nothing more than a trace (or a copy) of the displaced DP controller. In light of this, the reductionist approach does not seem plausible for the simple reason that there is no partial raising. The notion is theoretically incoherent (raise only a chunk of reference?) and empirically unattested.

In order to explain PC, while preserving the underlying idea that (obligatory) control instantiates raising, Hornstein (2003) introduces Meaning Postulate, as stated in (8) below:

If "DP Vs [тр to VP]" then "DP Vs [тP DP and some contextually specified others to VP]"

Obligatory Control is derived via movement of the controller through multiple thematic positions up to the case position in narrow syntax, (9a):

(9a) John wants [ $\{$ John $\}$ to meet at six $]$

(9b) John wants [ $\{$ John and some contextually specified others $\}$ to meet at six]

\footnotetext{
${ }^{10}$ Unfortunately, space limitations preclude me from spelling out all the ins and outs of the analyses in Lan-
} dau $(2004,2007)$. However, for my purposes, these details are immaterial. 
As regards the derivation, there is no difference between Exhaustive Control and Partial Control, the contrast is due to the application of the postsyntactic Meaning Postulate, sensitive to the lexical semantics of particular embedded verbs, such as meet, which require plural subjects. Thus (9a) is the input to the Semantic Postulate that returns (9b). The postulate must apply here, as otherwise narrow syntax on its own could not produce a semantic representation that is compatible with the selection requirements of the embedded verb.

Although Hornstein himself concedes that this solution is crafted specifically to cover the cases of PC, the mechanism works and what is more it provides a satisfactory solution to a number of problems that beset the ATC, including the Parasitic PC Effects the account of which will be spelled out in the following section. ${ }^{11}$ However, prior to attending to the PPCE let me first briefly touch upon a technical implementation of Hornstein's Meaning Postulate as presented in Rodrigues (2007), which will motivate the proposed analysis of the PPCE.

\subsection{The move-and-strand approach}

On the basis of mismatch between the syntactic and semantic gender features of PRO in constructions with epicene nouns in Romance languages, Rodrigues (2007) argues that PC results from movement of a DP controller followed by stranding of the adjoined pronoun which is construed as an associate plural to the controller. ${ }^{12}$ Let us adapt her analysis of PC in Romance languages to the following English example of PC:

(10a) John ${ }_{1}$ wants $\left[\mathrm{PRO}_{1+}\right.$ to meet in the morning].

(10b) $\quad[\mathrm{TP}$ John $[\mathrm{vP}\{\mathrm{John}\} \mathrm{v}$ [vp wants [TP $\{$ John $\}$ T-to [wollP woll [vр [vP [DP pro $\{$ John $\}]$ [v meet]] [pp in the morning]]]]]]].

The underlying assumption of Rodrigues's proposal is that the DP controller starts its derivational life as part of a more complex DP which also includes a null associative plural pronoun along with the controller, as shown in (11):

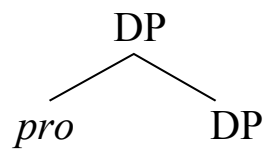

\footnotetext{
${ }^{11}$ For a fuller exposition of the problematic aspects of the ATC and the alternative solutions proposed within the MTC, see Witkoś and Snarska (2008).

${ }^{12}$ Space limitations preclude me from fleshing out all the details of her analysis. In a nutshell, Rodrigues shows that $\mathrm{PRO}_{1+}$ is both syntactically and semantically singular. She also challenges the division of control verbs into $\mathrm{PC}$ and $\mathrm{EC}$ ones.
} 
The null pronoun pro bears resemblance to the associative morphemes -tachi in Japanese and -men in Chinese which, when attached to DPs, trigger the plural associative reading of these DPs:

(12a) Yamada-sensei-wa Taroo-tachi-o syokuzi-ni syootai-sita (Japanese) Hamada-teacher-TOP Taro-PL-ACC meal-to invited 'Professor Yamada invited Taro and those in his group for dinner.'

(10b) Xiao Qiang-men shenme shihou lai? XiaoQiang-PL what time come

(Chinese)

'When are XiaoQiang and the others coming?'

Rodrigues suggests that pro in (11) behaves in the same way and yields a plural reading of the DP it is adjoined to. In the course of the derivation of a control structure, pro is left behind by the controller DP moving out of the base adjoined structure in [Spec, vP] into [Spec, TP] of its own clause and further into a new thematic position in the matrix clause, reaching finally [Spec, TP] in the matrix for EPP and case reasons.

(13)

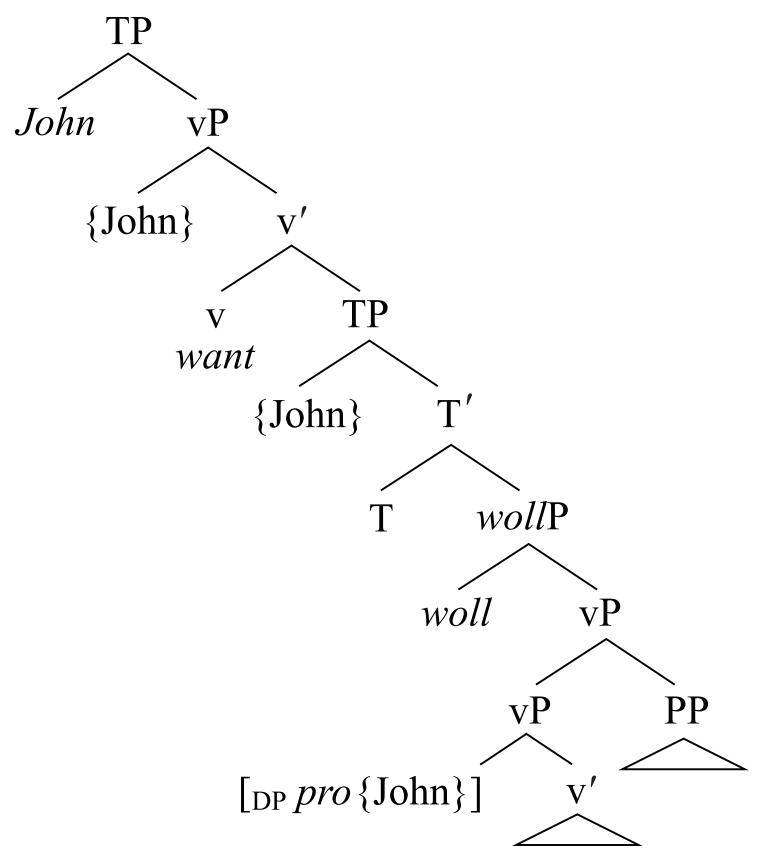


At this juncture, two points are of crucial importance. First, in her analysis, Rodrigues follows Wurmbrand (2007), who convincingly contends that infinitives are tenseless, containing only the abstract modal woll partaking of a quasi-future aspect. ${ }^{13}$ Second, the associative pronoun is stranded since its semantics requires that it stay within the scope of woll. ${ }^{14,15}$

Having laid out the underlying tenets of the move-and-strand approach, let us finally address the PPCE.

4. What to do with Parasitic PC Effects?

\subsection{Empirical facts}

Let us take a closer look at Adjunct Control cases, which seem to be fraught with unforeseen problems concerning PC. Hornstein (2003) shows that, although AC infinitives can easily have an independent tense specification, (14a), this cannot be a sufficient condition for PC licensing, (14b-c):

(14a) John saw Mary yesterday (in order) to leave early tomorrow.

(14b) *John1 saw Mary after/without [PRO1+ meeting/gathering at six].

(14c) ${ }^{*} \mathrm{John}_{1}$ saw Mary early (in order) $\left[\mathrm{PRO}_{1+}\right.$ to meet/gather at Max's at six].

Otherwise Adjunct Control (in subject oriented purpose clauses) shows the hallmarks of Obligatory Control, such as the presence of an antecedent, sloppy reading under ellipsis and de se interpretation:

(15a) John ${ }_{1}$ saw Mary 2 [in order $\mathrm{PRO}_{1 / *_{2}}$ to get a medal].

(15b) John 1 saw Mary in order $\mathrm{PRO}_{1}$ to get a medal and Bill did too.

${ }^{13}$ Rodrigues originally places woll in the T position, whereas I allow the woll element to project on its own. Needless to say, I still cling to the idea that, although syntactically projected, Tense is semantically empty. An anonymous reviewer points out that on this view the matrix predicate cannot select the wollP since the latter clearly violates a condition of locality on selection. However, woll is a temporal element yielding posteriority. As such, it is inextricably linked to the notion of tense, be it syntactic or semantic. Consequently, one may argue that, indeed, a selectional feature of the verb is satisfied upon merger of the complement TP, but that the corresponding feature on $\mathrm{T}$ is shared by the woll $\mathrm{P}$ by virtue of the latter in fact representing Tense in the non-finite complement. In such a case, both $\mathrm{T}$ and woll represent one temporal domain (although a split one) and the verb, selecting the head of TP, automatically selects woll.

${ }^{14}$ Rodrigues does not elaborate on this restriction.

${ }^{15}$ As one may have already noticed, Rodrigues's proposal is similar in spirit to the view of control as movement and stranding postulated in Kayne (2002). He argues that PRO and its controller originate as a single constituent within the non-finite clause and then the lexical DP moves into the matrix subject position, marooning the controllee (the process is similar to clitic doubling). 
(15c) Only John saw Mary in order to get a medal.

All in all, the run-of-the-mill PC into adjunct clauses is impossible, as witnessed in $(14 \mathrm{~b}-\mathrm{c})$. Surprisingly, once adjunct control is coupled with PC in a complement clause, PC in the adjunct clause becomes licit, a phenomenon that I will call Parasitic PC Effects (henceforth, PPCE):

(16a) Peter ${ }_{1}$ wants $\left[\mathrm{PRO}_{1+}\right.$ to meet in the old barn $]$ so as/in order not $\left[\mathrm{PRO}_{1+}\right.$ to gather in a public place].

(16b) Peter ${ }_{1}$ wonders where $\left[\mathrm{PRO}_{1+}\right.$ to meet $]$ so as/in order not $\left[\mathrm{PRO}_{1+}\right.$ to gather in a public place].

Provided there is a right context, the sentences in (16) are licit (both adjunct clauses scope under want and wonder in (16b) and (16c), respectively), which is most surprising in light of the unavailability of run-of-the-mill PC into adjunct clauses, as illustrated in $(14 \mathrm{~b}-\mathrm{c})$. Needless to say, the ATC faces a problem in (16). What is its source? As mentioned in section 2, control seen as Agree is sensitive to islands. If PC is triggered only when the matrix probe ( $\mathrm{T}$ in the case of (16)) establishes a relation with the embedded goal (T-Agr), how is it possible that PC is licensed in the adjunct clause which is an unpenetrable domain and thus does not sanction Agree with the infinitival T-Agr? Consequently, the unexpected PC reading in the case of PPCE is shrouded in mystery within the ATC. ${ }^{16}$ In the next section I will show that the MTC is free of such a puzzle with the PPCE receiving a straightforward explanation and constituting thus a strong argument in favor of the MTC.

\subsection{The analysis}

The problem with the MTC (in the version just presented) and the ATC is that both approaches incorporate the idea that $\mathrm{PC}$ environments must be selected by matrix verbs. Put differently, PC is licensed only in complements. ${ }^{17}$ Consequently, neither of them is able to account for the PPCE which crucially trigger PC reading in non-complements.

\footnotetext{
${ }^{16}$ A possibility open to the ATC approach, would be to treat PPC effects as a case of NOC, where the silent logophoric pronoun pro refers to the pragmatically salient controller of the OC PRO or the OC PRO itself and the semantic plurality is somehow licensed pragmatically. But this move would undoubtedly sap the explanatory power of Landau's approach: why is it the case that the null subject in (14a) in the adjunct clause participates in obligatory control, whereas the one in (16) is a logophor representing NOC?

${ }^{17}$ This state of affairs results form the fact that in the case of the ATC Agree, being sensitive to islands, cannot penetrate non-complements. As far as the MTC is concerned, the Meaning Postulate built in the lexical entry of PC verbs can exert its influence only on arguments of these verbs.
} 
To cater for the relevant data, I would like to suggest an analysis that uses the refined derivational mechanism as employed by the move-and-strand approach, pointing thus to the MTC being a better alternative than the ATC to the PC problem.

Although Rodrigues (2007) remains silent on the details of the licensing of associative pro, apart from proposing that it must remain in the scope of woll, I submit that the licensing condition on this type of pro is more complex. Namely, that it can only be licensed by a wollP selected by the matrix verb, otherwise associative pro and PC effects should appear in plain Adjunct Control, where wollP can appear and license an event predicate, (17a). Despite the presence of wollP and an event predicate, Adjunct Control cannot independently support a PC reading $(17 b)$ :

(17a) John left the room to finish his dinner right now.

(17b) *John left the room to meet in the pub.

Thus the associative pro not only needs to find itself in the scope of woll, but the wollP must be selected. For instance, in (18) the infinitive licensing the projection of wollP is selected by the matrix verb desire:

(18) $\quad[$ тр Mary [vр desires [TP \{Mary\} T-to $[$ woll woll $[\mathrm{vP}[$ pro $\{$ Mary $\}$ pro $]$ meet in the lounge]]]]] $]^{18}$

In regular cases this is sufficient, but in the case of parasitic PC much more is required: a sideward movement of the controller from within the adjunct to the complement clause and then up to the matrix clause. ${ }^{19}$ Additionally, the parasitic PC mimics the behavior of the complement in (19a) and requires that the controller in the [Spec, $\mathrm{TP}]$ position be interpreted as both syntactically and semantically singular:

\footnotetext{
${ }^{18}$ Notice that I do not follow Rodrigues, assuming that pro is right-adjoined to Mary. This presupposition is a result of the following reasoning: the relevant concatenating process cannot exemplify set-Merge in the sense of Chomsky (2004) with Mary possessing no selectors which would be satisfied in the aftermath of Merge with the null pronominal. Hence, it may be inferred that the type of Merge which is at play in (18) is pair-Merge. However, I suggest, pace an anonymous reviewer, that it is pro which is adjoined to Mary, not the other way round. As standardly assumed, adjuncts cannot receive a thematic role on their own and cannot satisfy features (subcategorization features, EPP features, phi-features etc.). Hence, it appears more plausible that what functions as an adjunct is pro, not Mary. Furthermore, the associative pro is invariably semantically conditional upon a focal referent with which it is associated. As regards the direction of projecting the adjunction structure, I propose it is right-adjunction since I treat the associative plural markers such as -ney in Korean or -tachi in Japanese as the lexicalized versions of the associative pro:

(i) Inho-ney-ka pelsse ttena-ass-ta. (Korean)

Inho-PL-NOM already leave-PST-DC

'Inho and those associated with him/her already left.'

${ }^{19}$ Exactly as in the analyses of sideward movement in parasitic gap constructions (Nuñes 1995, 2001) and relative clauses (Kim 1998; Hornstein 2000).
} 
(19a) A vítima quer se encontrar bêbada/*bêbadas the victim-FEM wants-3sg SE meet-INF drunk-FEM,sg/drunk-FEM,pl

*bêbado/*bêbados drunk-MASC,sg./drunk-MASC, pl.

(Brazilian Portuguese)

'The victim wants to meet (with somebody else) drunk.'

(19b) *?Peter wants to meet in a dark room so as to kiss each other.

Example (19b) shows that there must be separate wollP in the adjunct clause and a movement of the controller to the embedded [Spec, TP], stranding the collective pro in the scope of woll. After all, the plural anaphor is not licensed.

Consider the derivational details of (20). First, the adjunct clause is formed, with a non-selected wollP. Within the adjunct the controller moves up to [Spec, TP] to satisfy the EPP feature:

(20) $\left[\mathrm{CP}\right.$ C so as $[\mathrm{TP}[\mathrm{DP} \text { Peter }]]_{\mathrm{T}}$ not to $\left[\right.$ woll $\mathrm{p}$ woll $\left[_{\mathrm{vP}}[\mathrm{DP}\{\right.$ Peter $\}$ pro $][\mathrm{vP}$ gather in a public place]]]]

Next, the controller is moved sideward to another object under construction on the derivational workbench and forms another complex DP, (21a). Further, this complex DP is placed in the thematic subject position of the complement infinitive, (21b). From this position it moves to [Spec, TP] within its own clause and then further to the matrix [Spec, vP] and finally its surface position, producing the complex representation in $(21 \mathrm{c})::^{20}$

(21a) $\quad[$ DP $[$ Peter $]$ pro $]$

(21b) $\left[{ }_{\mathrm{TP}}[\mathrm{DP} \text { Peter }]_{\mathrm{T}}\right.$ to $\left[{ }_{\text {wollp }}\right.$ woll $\left[{ }_{\mathrm{vP}}[\mathrm{DP}\{\right.$ Peter $\}$ pro $] \mathrm{v}[\mathrm{vP}[\mathrm{vP}$ meet $][\mathrm{PP}$ in the old barn]]]]]

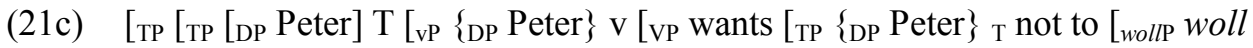
[vP [DP \{Peter $\}$ pro $] \mathrm{v}$ [vp[vp meet] [pP in the old barn]]]]]]]] [CP $\mathrm{C}$ so as [тр $\{$ DP Peter $\}$ т not to [woll woll [vP [Dp $\{$ Peter $\}$ pro] [vP gather in a public place]]]]]]]

It will be noticed that I postulate that the movement of the controller within the adjunct also strands the collective pro. This may be the property of an unselected wollP that it

\footnotetext{
${ }^{20} \mathrm{I}$ assume that the purpose clause is adjoined to matrix TP and omit the projection of NegP for conven-
} ience. 
licenses the interpretation of the associative pro only provisionally, on condition that this licensing is confirmed in the selected clause:

(22) The Parasitic PC Postulate:

Unselected wollP licenses the associative pro on DP only when this licensing is subject to confirmation on the same DP by a selected woll $\mathrm{P}^{21}$

Certainly, the postulate in (22) is not a principle of the derivation running in narrow syntax; it smacks of look-ahead and derivational globalizm. Yet, a principle of this type can apply to the complete representation of example (16) on the LF side of grammar, within the semantic component. ${ }^{22}$

The Postulate in (22) exemplifies a situation well known from the study of syntax, for instance $w h$-movement (e.g. Kayne 1984; Chomsky 1986; Nuñes 1995, 2001). This dependency can best hold over long distance if the foot of the $w h$-chain is placed within a complement domain and it cannot hold if the foot of the chain is placed within an adjunct or subject:

(23a) Which book did Susan want [complement to file $t_{w h}$ ]

(23b) *Which book did John leave London [adjunct without reading $t_{\mathrm{wh}}$ ]

(23c) *Which man does [subject everyone who meets $t_{\text {wh }}$ inspire you

(24a) Which book did Susan want [to file $t_{w h}$ ][without reading $t_{w h}$ ]

(24b) Which man does [everyone who meets $t_{\mathrm{wh}}$ ] gets to like $t_{\mathrm{wh}}$ at once

\footnotetext{
${ }^{21}$ Obviously, the statement on the licensing of the selected and non-selected woll has yet to be formalized in the future research.

${ }^{22}$ An anonymous reviewer points out that, provided that syntax is to be crash-proof, there is still no narrow syntax-internal mechanism to block the derivation of PC in simple adjunct clauses like *John saw Mary early in order to meet at Max's at six. However, the reviewer has overlooked the explanation of this example in the paper. I have already argued in section 4.2 that pro can only be licensed by a wollP selected by the matrix verb, which can also be deemed to be a semantic condition, considering that derivational constraints operate only at the local level. On the whole, the system envisioned here is not crash-proof. The syntax can compute PC configurations which are otherwise semantically deviant. However, this is a job of the interpretive principles to filter out the unacceptable constructions. In fact, the issue under consideration is much more complex: is the crash-free syntax conceptually desirable? Possible. Everything hinges on how one interprets optimality. But even granting that the derivational system is such that it generates only products which satisfy the interface requirements (exemplifying thus pervasive redundancy), we cannot exclude a possibility that in some cases the language faculty utilizes solely design specifications of the interfaces without showing how the derivational system attains the effects of these requirements. After all, the result is the same under both scenarios. Of course, if one wants to maintain the idea of the crash-proof syntax, the theory advanced in this paper would have to suggest a computational device replacing the filters. All in all, the veracity of the crash-free-syntax proposal is beyond the scope of the paper.
} 
As the examples in (24) show, a combination of an extraction of one and the same element from within the complement domain and the island gives acceptable results, somehow the illicit movement is "repaired". Analogously, an illicit case of stranding of the associative pro under an unselected wollP is repaired by its further legitimate stranding by the same controller. ${ }^{23}$

From a representational point of view, my proposal can also be taken as an instantiation of Richards' (1999) Principle of Minimal Compliance. Namely, one licit case of a more local licensing of the collective pro in the scope of a selected wollP paves the way for an otherwise illicit licensing of the more distant associative pro in the scope of an unselected wollP, provided the controller, with which pro is pair-merged, is identical in both relations.

In the way of conclusion to this section, I believe to have shown two interesting properties of Partial Control. First, the coupling of PC readings in adjunct clauses with PC effects in the complement clause points to the obligatory control (OC) status of Adjunct Control. Second, parasitic PC effects seem to require an analysis in the form of sideward movement of the controller. The Agree Theory of Control finds itself at a disadvantage in this case, as the matrix T or v Probes cannot access PRO within the adjunct.

\section{Final remarks}

In this paper, I introduced a new observation about $\mathrm{PC}$ into adjunct clauses, a phenomenon that I dubbed Parasitic PC Effects. It was argued that these problematic data are best explained when one adopts the approach framed within the Movement Theory of Control. More precisely, drawing on Rodrigues (2007), I developed an analysis which crucially assumes the presence of the woll projection in the structure of a non-finite clause and an interarboreal movement of the DP controller out of an adjunct clause. What is more, the DP itself must be part of a more complex DP being comprised also of a null associative pronoun, which evokes a plural interpretation of the controller. The DP antecedent, when moving to higher positions in a derivation, strands the associative pronoun which has to find itself within the scope of the modal woll.

The presented analysis also has some theoretical implications. It shows that the carefully and meticulously constructed syntactic view of PC within the ATC is in itself inadequate for a descriptive and explanatory account of PC. As such, it cannot consti-

${ }^{23}$ The PPC effect is not obligatory with PC verbs but only optional:

(i) John wants $\{\mathrm{John}+1\}$ to meet in the pub $\{\mathrm{John}\}$ to watch the match.

John alone may be watching the match during the meeting with his friends in the pub. For this derivation we propose that no complex DP is formed in the adjunct clause but it is created later, after the sideward movement of John from the adjunct clause. 
tute a compelling and potent argument against the MTC which, employing both syntax and semantics, can successfully handle the PPCE. And this, in turn, defies any purely syntactic view of control in general. After all, PC, however inconvenient it is, is a type of control and as such has to receive an explanation. But syntax itself seems to be not enough.

\section{REFERENCES}

Bondaruk, A. 2004. PRO and Control in English, Irish and Polish: A minimalist analysis. Lublin: Wydawnictwo KUL.

Bondaruk, A. 2006. "Minimalist approaches to Control: A critical overview". Research in Lanuguage 4. 91-126.

Bošković, Ž. 1997. The syntax of nonfinite complementation. Cambridge, MA: MIT Press.

Bowers, J. 2005. On reducing Obligatory Control to movement. (Ms., Cornell University.)

Chierchia, G. 1984. Topics in the syntax and semantics of infinitives and gerunds. (Unpublished PhD dissertation, University of Massachusetts, Amherst.)

Chomsky, N. 1982. Lectures on government and binding. Dordrecht: Foris.

Chomsky, N. 1986. Knowledge of language: Its nature, origin and use. New York: Praeger.

Chomsky, N. 2000. "Minimalist inquiries. The framework". In: Martin, R., D. Michaels and J. Uriagereka (eds.), Step by step: Essays in honor of Howard Lasnik. Cambridge, MA: MIT press. $89-156$.

Hornstein, N. 2000. Move! A minimalist theory of construal. Cambridge, MA: Blackwell.

Hornstein, N. 2003. “On Control”. In: Hendrick, R (ed.), Minimalist syntax. Oxford: Blackwell. $6-81$.

Hornstein, N. 2006. "A short note on NOC". University of Maryland Working Papers in Linguistics 14. 39-46.

Janke, V. 2008. "Control without a subject". Lingua 118. 82-118.

Kayne, R. 1984. Connectedness and binary branching. Dordrecht: Foris.

Kayne, R. 2002. "Pronouns and their antecedents". In: Epstein, S.D. and T.S. Seely (eds.), Derivation and explanation in the Minimalist Program. Oxford: Blackwell. 133-166.

Kim, K. 1998. Anti-Connectivity. (Unpublished PhD dissertation, University of Maryland, College Park.)

Landau. I. 2000. Elements of control. Structure and meaning in infinitival constructions. Dordrecht: Kluwer.

Landau. I. 2003. "Movement out of control". Linguistic Inquiry 34. 471-498.

Landau, I. 2004. "The scale of finiteness and the calculus of control". Natural Language and Linguistic Theory 22. 811-877.

Landau, I. 2006. "Severing the distribution of PRO from case". Syntax 9. 153-170.

Landau, I. 2007. Two routes of control: Evidence for case transmission in Russian. (Ms., Ben Gurion University, Tel-Aviv.)

Lawler, J. 1972. A problem in participatory democracy. Bloomington: Indiana University Linguistics Club.

Manzini, R. and A. Roussou. 2000. “A minimalist theory of A-movement and control”. Lingua 110. 409-447.

Martin, R. 1996. A minimalist theory of PRO and control. (Unpublished PhD dissertation, University of Connecticut, Storrs.) 
Martin, R. 2001. "Null case and the distribution of PRO". Linguistic Inquiry 32. 141-166.

Nuñes, J. 1995. The copy theory of movement and linearization of chains in the minimalist program. (Unpublished PhD dissertation, University of Maryland, College Park.)

Nuñes, J. 2001. "Sideward movement". Linguistic Inquiry 32. 303-344.

Pires, A. 2001. The syntax of gerunds and infinitives: Subjects, case and control. (Unpublished $\mathrm{PhD}$ dissertation, University of Maryland, College Park.)

Polinsky, M. and E. Potsdam. 2002. "Backward control". Linguistic Inquiry 33. 245-282.

Richards, N. 1998. "The Principle of Minimal Compliance". Linguistic Inquiry 29. 599-629.

Reinhart, T and E. Reuland. 1993. "Reflexivity". Linguistic Inquiry 24. 657-720.

Rodrigues, C. 2007. Agreement and flotation in Partial and Inverse Partial Control configurations. (Ms., MIT, Cambridge, MA.)

Rosenbaum, P. 1967. The grammar of English predicate complement constructions. Cambridge, MA: MIT Press.

Sauerland, U. and P. Elbourne. 2002. "Total reconstruction, PF movement, and derivational order". Linguistic Inquiry 33. 283-319.

Snarska, A. 2007. "Partial control - Is it really a grammatical chimera?" In: Arabski, J., D. Gabryś-Barker and A. Łyda (eds.), Studies in language and methodology of teaching foreign languages (vol 1). Katowice: University of Silesia Press. 106-122.

Stowell, T. 1982. "The tense of infinitives". Linguistic Inquiry 13. 561-570.

Williams, E. 1980. "Predication". Linguistic Inquiry 11. 203-238.

Witkoś, J. and A. Snarska. 2008. "On Partial Control and Parasitic PC Effects”. SKASE Journal of Theoretical Linguistics 5. 42-75.

Wurmbrand, S. 2007. "Infinitives are tenseless". U. Penn Working Papers in Linguistics. 13(1). 407-420. 